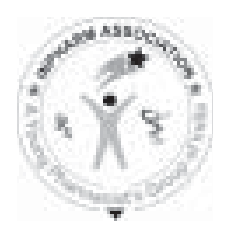

\title{
JVP
}

\section{Pharmaceutical E-Learning: Precepts, Retrospect and Prospects}

\author{
Singh B, Kapil R, Katare OP \\ University Institute of Pharmaceutical Sciences (UGC Centre of Advanced Studies) Panjab University, \\ Chandigarh - 160 014, India
}

Address for correspondence: Prof. Bhupinder Singh Bhoop; E-mail: bsbhoop@yahoo.com

\begin{abstract}
The domain of pharmaceutical sciences is a highly dynamic one with the "half-life" of pharmaceutical information declining constantly. Be it the drug industry or the academic institutes, it is mandatory to keep abreast with the latest developments, and update our curricula and training contents accordingly. The traditional "chalk and talk" methods though are satisfying the objectives, yet have proved invariably to be monotonous and resourceintensive. The judicious use of web-based e-technologies in imparting training to the university students has been found to be interesting as well as rewarding. Being interactive, e-Learning in this context, presents the material in a structured manner and permits the student to progress at one's own pace taking an individual path through the lesson. Globally, the pharmaceutical institutes and industries have already recognized the enormous potential of e-Learning, and are applying it too in the mundane training of their skilled workforce. A transition from the erstwhile "hard" educational course materials in the printed form to the current "soft" materials on CDs and DVDs has already begun. Nevertheless, the pharmaceutical institutes and corporates of India are yet to harvest completely the utility of these effective and cost-effective e-Learning tools. But of late, the winds have started blowing in the favorable direction. With an increasing proportion of the young, computer-aware and "networked" population coupled with favorable gubernatorial policies, the future of e-Learning in India seems to be quite bright.
\end{abstract}

Key words: Computer-aided learning, web-based learning, intelligent tutoring, computer-aided instructions, pedagogy, technology-enhanced learning, continuing education

DOI: $10.4103 / 0975-1483.55740$

We are amidst an e-age. Almost every walk of our routine life, especially almost every science discipline, has been significantly affected with the advent of this e-revolution ${ }^{[1]}$. A "networked computer system" has made the lion's contribution in the establishment of information industry, known to be one of the biggest around the globe. Today, a microcomputer, capable of e-communication, is considered as an indispensable gadget not only at the industrial houses, business establishments, offices, but in homes as well. The Internet is expanding its base at a winged pace with jargons such as cyberspace, virtual libraries, web-link, netizen, cyber crime and webinars becoming a common place.

\section{FUNDAMENTAL PRECEPTS}

Although e-media has significantly influenced every boulevard of professional life, its use as an instructional delivery device is the most noteworthy among all its applications. The erstwhile precepts of last decade such as Computer-aided Education (CAE), Computer-aided Learning (CAL) or Computer-aided Instructions ${ }^{[2]}(\mathrm{CAI})$ have evolved today into a newer and broader paradigm of "e-Learning."

Going by its literal implication, e-Learning is a category 
of technology-supported education or learning, in which the medium of instruction is through digital sources. In other words, e-Learning is a planned teaching or learning experience that uses a wide spectrum of technologies, mainly Internet or computer-based, to eventually reach the learners, even those located distantly. This pedagogy empowered by digital technology is used interchangeably in a wide variety of contexts. In most universities, e-Learning is used to define a specific mode to attend a course or program of study, in which the students rarely attend faceto-face or have on-campus access to educational facilities, as they study online. In the corporate sector, however, it refers to a blend of strategies that use the company network to deliver training courses to its skilled employees. Holistically, e-Learning can be considered as a technologydriven pedagogical process of imparting contextual training to pupils/work force, as represented in Figure 1.

The process of e-Learning offers exceptional capabilities of handling, storage, treatment and presentation of a variety of data too, thus holding tremendous promise in enhancing the work pattern of a professional. The word " $\mathrm{e}$ " could be interpreted to imply exciting, energetic, enthusiastic, emotional, extended, excellent and educational, besides "electronic," that is, a conventional interpretation. ${ }^{[3]}$ Almost all the major spheres of pharmaceutical service in the developed world are persistently employing e-Learning for varied activities. ${ }^{[4,5]}$ Verily, e-Learning is not an entirely new concept, but the old concept of CAL or CAE or CAI, amalgamated with newer vistas and technologies; an old wine formulated into a newer cocktail after blending it with a few more flavors. The judicious use of e-Learning in imparting training to the students has been found to be interesting as well as rewarding at various institutions across the world, especially in the developed nations.

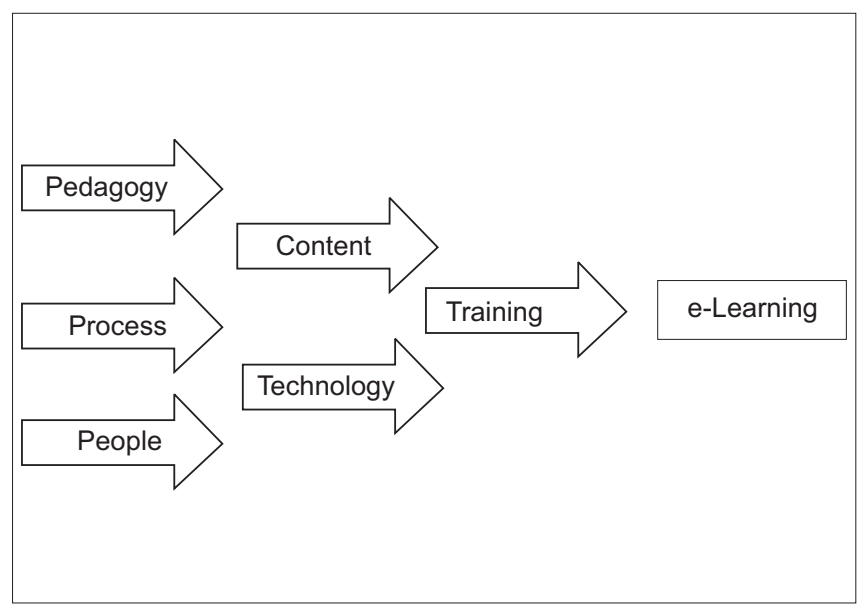

Figure 1: The holistic concept of e-Learning

\section{Development of e-learning material}

Two types of communication technologies are generally employed during the development of e-Learning material, viz. asynchronous and synchronous. Asynchronous activities use technologies such as blogs, wikis and discussion boards. Here, the motive is that participants engage in the exchange of ideas or information without the dependence of other participants' involvement at the same time. E-mail is also asynchronous in that mail can be sent or received without having both the participants' involvement at the same time. Synchronous activities involve the exchange of ideas and information with one or more participants during the same period of time. A face to face discussion is an example of synchronous communications. Such activities occur with all participants joining in at once, as with an online chat session. Virtual classrooms and e-meetings often use a blend of synchronous and asynchronous communication technologies.

Development of a student-friendly e-Learning package is known to be quite teacher-unfriendly. ${ }^{[6]}$ When beginning to create e-Learning content, some pedagogical approaches need to be evaluated. Overall, simpler approaches make it easier to create content, but are characterized by lack of flexibility, richness and downstream functionality. On the other hand, complex pedagogical approaches can be difficult to set up and slow to develop, though they have the potential to provide more engaging learning experiences for students. Somewhere, in-between these extremes, is an ideal pedagogy that allows a particular educator to effectively create educational materials while simultaneously providing the most engaging educational experiences for students. It is possible to use a rational amalgamation of various approaches for e-Learning, which focus on diverse elements of pedagogy:

- Instructional, that is, a traditional curriculum-focused pedagogy of instruction developed by a centralized educating group or a single teacher.

- Social-constructivist, that is, a collaborative approach that opens educational content creation to a wider group including the students themselves. This pedagogy is especially well-afforded by the use of discussion forums, blogs, wiki and on-line collaborative activities. The One-Laptop-Per-Child Foundation attempted to use this constructivist approach in its project.

- Cognitive, which focuses on the cognitive processes involved in learning as well as on how the brain works.

- Emotional, which focuses on the emotional aspects of learning, such as motivation, engagement and fun.

- Behavioral, which focuses on the skills and behavioral outcomes of the learning process, for example, role- 
playing and application to on-the-job settings.

- Contextual focuses on the environmental and social aspects, which can stimulate learning, especially during interaction with other people, collaborative discovery and the importance of peer support as well as pressure.

The e-Learning lessons are generally designed to guide students through information or to help students perform specific tasks. Information based e-Learning content communicates information to the student. Instances include the content that distributes the history or facts related to a service, company or product. In the information-based content, there is no specific skill to be learned. In performance-based content, the lessons build off of a procedural skill in which the student is expected to increase proficiency.

A recent trend in the development of e-Learning products has been "screencasting." There are many screencasting tools available, but the latest buzz is all about the webbased screencasting tools, which allow the users to create screencasts directly from their browser and make the video available online so that the viewers can stream the video directly. The advantage of such tools is that it gives the presenters the ability to show their ideas and flow of thoughts rather than simply explain them, which may be more confusing when delivered via simple text instructions. With the combination of video and audio, the expert can mimic the one-on-one experience of the classroom and deliver clear and complete instructions. From the learners' perspective, this provides the ability to pause and rewind and gives the learner the advantage to move at their own pace, something a classroom cannot always offer.

\section{PHARMACEUTICAL E-LEARNING: A RETROSPECT}

Since 1789, when pharmacy was first taught as a complete discipline at School of Pharmacy in Philadelphia, the profession has undergone metamorphosis from the traditional drug compounding to the modern blend of pharmaceutical sciences. Consequently, for grooming a pharmaceutical scientist, a student has to be imparted training on a whole gamut of clinical as well as technological facets related to the drugs. In the implementation of many of these current concepts, such as molecular drug design and combinatorial chemistry, high-throughput screening, pharmacokinetic modeling, novel drug delivery, experimental demonstrations using animals or animal tissues, intellectual property rights and drug information services, a computer interface is customarily considered to be imperative. The schools of pharmacy in the developed world have either modified or are in the process of modifying their undergraduate and graduate curricula to emphasize the impact of this web-based computerization on the profession.

Since the last three decades, the formidable advancements in information technology (IT) have come to the rescue of a pharmacy teacher in performing the arduous task of disseminating explicit information on the multitudinous aspects of medicinal agents in a superior manner. Accordingly in pharmaceutical sciences, e-Learning is not a new phenomenon in North America and Europe. Scores of reports on use of IT in teaching pharmaceutical subjects have appeared in literature, including the erstwhile CAI packages. Most software and web material have been written for IBM-PCs, a select list of some popular software for teaching pharmaceutical concepts is displayed in Table 1.

Many of these softwares not only provided the pertinent information in response to user prompts, but evaluated student performance by asking varied pertinent MCQs. ${ }^{[7-9]}$ Some of these are even Intelligent Tutoring Systems (ITS), which can generate and communicate responses to answers to any user queries on the subject, while some others are Multimedia packages. With the help of these software, e-Learning has been frequently employed to teach intricate scientific concepts such as pharmacokinetic modeling, animal physiology simulations, clinical pharmacy, rheology and microbiology, in a more effective and elegant manner. Albeit the Macintosh PC has also been employed globally in pharmacy circles owing to its high resolution graphics, only a couple of reports on Apple compatible e-Learning package have been found in literature.

The scientists at diverse international platforms have accentuated the need to use IT in pharmacy instruction and refurbish the attitude of the pharmaceutical instructors to encompass e-Learning in teaching. ${ }^{[10]}$ The prominent factors, driving the use of computers in pharmacy education, are to ease out the burden of excessive teaching on students, overcome the dwindling resource base and to capitalize on new web-based technologies. As a consequence, an organization, Pharmacy Consortium for Computer-Aided Learning (PCCAL), United Kingdom, was set up in 1992 with the sole purpose of developing computer-based and web-based software application tools for pharmacy pupils. The consortium won liberal funding, to the tune of several million sterling pounds, from various Teaching and Learning Technology Programs (TLTPs) of the UK Government. The spurt in popularity of e-Learning in pharmacy colleges throughout the subcontinents of Europe, North America, Australia and some parts of Asia 
Singh, et al. J Young Pharm. 2009;1(2):99-109

Table 1: Various e-Learning computer-aided education software for pharmaceutical applications

\begin{tabular}{|c|c|c|c|}
\hline Software & Language & Pharmaceutical Application & Year \\
\hline--- & MATHCHAT & Drug stability kinetics & 1975 \\
\hline PEX & BASIC & Fundamentals of clinical pharmacy & 1978 \\
\hline--- & COBOL & Prescription record keeping & 1984 \\
\hline--- & --- & Pharmacy practice & 1984 \\
\hline--- & --- & Clinical pharmacy & 1984 \\
\hline--- & --- & Identification of pathogens & 1984 \\
\hline--- & --- & Drug pharmacokinetics & 1985 \\
\hline--- & --- & Drug dose monitoring in patients & 1985 \\
\hline--- & --- & Pharmacokinetic concepts & 1985 \\
\hline CALPCOKIN & PLATO & Drug disposition and pharmacokinetics & 1988 \\
\hline CAT & --- & Biopharmaceutics and patient drug monitoring & 1988 \\
\hline--- & --- & Clinical pharmacology to senior students & 1989 \\
\hline--- & --- & Drug pharmacokinetics & 1989 \\
\hline ENPHARM & --- & Community pharmacy and drug information & 1989 \\
\hline LINCTUS & --- & Patient health care & 1990 \\
\hline CYBERLOG & --- & Clinical pharmacology and patient care & 1991 \\
\hline ICEPAC & --- & Nebulizer use and therapy & 1991 \\
\hline PHARMLEX & --- & Pharmacy law in U. K. & 1991 \\
\hline--- & Authorware & Simulating physiology experiments on isolated animal tissue organs. & 1993 \\
\hline THERAPY & --- & Update on recent advances in therapeutics & 1994 \\
\hline Compass & & A shape-based machine learning tool for drug design & 1994 \\
\hline--- & --- & Use of OTC products in indigestion & 1995 \\
\hline PharmAssist & --- & Patient counseling through Multimedia & 1995 \\
\hline RESPOND & PROLOG & Expert system for aiding pharmacists in disease diagnosis & 1995 \\
\hline
\end{tabular}

(Japan, Singapore, etc.), led the consortium to institute PCCAL International, a global forum for e-Learners and implementers. Since 1996, it has even started bringing out an international quarterly periodical, PCCAL Bulletin. The only article in this bulletin from South-East Asian countries has been contributed by the corresponding author of this paper. The consortium has already launched several softwares for educating the undergraduate pharmacy students, some important ones are listed in Box 1.

Another major e-Learning package in the field of pharmaceutical sciences has been offered by British Pharmacological Society. Their package, "PharmaCALogy", is the product name for a range of over 50 software and Teachers' workbook titles produced by pharmacologists and pharmaceutical scientists. The products are designed to meet identified teaching needs and can be implemented in various ways to satisfy these needs. A tutor's guide has been available for each product and explains the variety of ways in which the material can be used to meet various learning objectives. The package covers extensive information on myriad pharmacological aspects such as drug metabolism, drug targets, neuropharmacology, cardiovascular system, simulations, clinical development, asthma and inflammation, as illustrated in Box 2.

Vital guidelines have been proposed for the course materials to form the basis for continuing education in pharmacy as six CRISIS criteria, namely, Convenient, Relevant, Individualized, Speculative, Inexpensive, and

Box 1: Some commercially available e-learning packages on pharmaceutical sciences from commercial and academic services (CoAcS), Bath, UK

\begin{tabular}{|c|c|}
\hline $\begin{array}{ll}\text { - } & \text { Autonomic Nervous System Tutor } \\
\text { - } & \text { Caric Calculations in Pharmacy } \\
\text { - } & \text { Coronary Circulation } \\
\text { - } & \text { Diseases of G. I. T. } \\
\text { - } & \text { Drug Dependence } \\
\text { - } & \text { Drug Metabolism } \\
\text { - } & \text { Drug Targets and Transduction Mechanisms } \\
\text { - } & \text { Experiments in Human Neuromuscular Physiology } \\
\text { - } & \text { Fundamentals of Data Collection } \\
\text { - } & \text { Foundation Organic Chemistry Assessment } \\
\text { - } & \text { Introduction to Mass Spectrometry } \\
\text { - } & \text { Introduction to Pharmaceutical Stereochemistry } \\
\text { - } & \text { Introduction to Recombinant DNA Technology }\end{array}$ & $\begin{array}{ll}\text { - } & \text { Introductory Pharmacokinetics Workshop } \\
\text { - } & \text { Labeling Dispensed Products with Supplementary Labels } \\
\text { - } & \text { Methods of Filling Hard Gelatin Capsules } \\
\text { - } & \text { Molecular Visualization and Stereochemistry } \\
\text { - } & \text { NMR Spectroscopy } \\
\text { - } & \text { Pharmaceutical Analysis-Titrimetry } \\
\text { - } & \text { Pharmaceutical Microbiology Assessment/Tutorial } \\
\text { - } & \text { Pharmacological Experiments on Guinea Pig Ileum } \\
\text { - } & \text { Pharmacy in Health Policy } \\
\text { - } & \text { Pharmacy Law and Ethics in UK } \\
\text { - } & \text { Prescriptions for Controlled Drugs in UK } \\
\text { - } & \text { Problem Solving in Community Pharmacy in U. K. } \\
\text { - } & \text { QSAR(Quantitative Structure Activity Relationships) } \\
\text { - } & \text { Radiochemistry and Radiopharmacy } \\
\text { - } & \text { GMP }\end{array}$ \\
\hline
\end{tabular}




\section{Box 2: Some commercially available pharmaceutical e-Learning packages on pharmacalogy}

\begin{tabular}{|c|c|}
\hline $\begin{array}{ll}\text { - } & \text { Central 5HT Transmission } \\
\text { - } & \text { Clinical Trials } \\
\text { - } & \text { Coronary Circulation } \\
\text { - } & \text { Drug Dependence } \\
\text { - } & \text { Drug Metabolism } \\
\text { - } & \text { Introduction \& How Receptors are Made and Regulated } \\
\text { - } & \text { Enzymes as Drug Targets } \\
\text { - } & \text { Steroid Receptors as Drug Targets } \\
\text { - } & \text { Uptake and Transporter Systems as Drug Targets } \\
\text { - } & \text { Tyrosine Kinase Receptors as Drug Targets } \\
\text { - } & \text { G-Protein Receptors as Drug Targets }\end{array}$ & $\begin{array}{ll}\text { - } & \text { Epidemiology and Pharmacoepidemiology } \\
\text { - } & \text { Ligand Binding } \\
\text { - } & \text { Movement Disorders } \\
\text { - } & \text { Observing and Recording Mouse Behaviour (Mouse Watch) } \\
\text { - } & \text { Peptidergic Transmission } \\
\text { - } & \text { Pharmacology of Inflammation } \\
\text { - } & \text { The pharmacology of Asthma } \\
\text { - } & \text { Schizophrenia } \\
\text { - } & \text { Simulated Water Maze } \\
\text { - } & \text { Suxamethonium } \\
\text { - } & \text { Synaptic Transmission in the Central Nervous System } \\
\text { - } & \text { Ion Channel Receptors as Drug Targets }\end{array}$ \\
\hline
\end{tabular}

Systematic. Most e-Learning-based training methods have been found to fulfill all the CRISIS criteria to a convincing extent. Surveys conducted among the pharmacy tyros undertaking e-Learning, observed it to be most economical in terms of cost as well as manpower. Another study on pharmacy students indicated that a majority of the novices found e-Learning lessons to be more self-monitoring, depersonalized, illustrative, vivid, organized and enjoyable.

Planned studies carried out on a large number of inservice pharmacists found e-Learning in continuing pharmacy education to be the most promising among varied instruction methodologies studied. The results are discernible in Table 2.

\section{PHARMACEUTICAL E-LEARNING: CURRENT GLOBAL TRENDS}

Globally, the user pharmacist's choice for e-Learning package has been significantly augmented by the declining hardware prices coupled with extension of its capabilities and capacities. Several authors have outlined numerous meritorious attributes of e-Learning vis-à-vis traditional classroom teaching of pharmaceutical precepts. Some of the stellar merits are enumerated as under:

- Structured, that is, information is well-organized and accessible to the user's choice

- Self-paced, which permits the user to progress through

Table 2: Overall rankings for teaching methodologies in continuing pharmacy education

\begin{tabular}{lc}
\hline Teaching Activity & Rank \\
\hline e-Learning & 1 \\
Video packages & 2 \\
Distance learning & 3 \\
Journal Articles & 4 \\
After hours lecture & 5 \\
Books & 6.5 \\
Leaflets & 6.5 \\
Face to face tutorial & 8 \\
Residential course & 9 \\
Others & 10 \\
\hline
\end{tabular}

the CAE lessons at his own pace

- Individualized, which allows the user to work privately without any interference

- Elegant, which uses the capability of computer for displaying information in catalogued form and/or portraying varied graphics, etc

- Interactive, which yields rapid responses to user prompts or queries

- Enjoyable, which overcomes monotony of the traditional black board approach

- Patient, which can be used repeatedly without any grudge till the user is satisfied

- Self-evaluating, which subsequent to the instructional sessions, permits the learner to take self-appraisal tests and evaluate his performance almost instantaneously

- Resource-effective, which requires less financial, laboratory and human (teaching and supporting) resources

- Dependable, that is, student has access to unambiguous documented knowledge overcoming occasional teacher inadequacies

- Dynamic, that is, the contents can be easily modified or upgraded depending upon the current professional requirements

- Simulative, which can simulate experimental situations that are expensive, dangerous, prolonged or unethical

- Numerically astute, which presents mathematical material laying more emphasis on concepts circumnavigating usually monotonous numeric complexities

- Convenient, which can be used at home or work place at a convenient time allowing intermittent pauses at will

- Environment-friendly, which avoids the use of paper notes and travel, thus reducing the overall pulp input and carbon output. With virtual notes instead of paper notes and online assignments instead of paper assessments, e-Learning is highly environment friendly.

- Borderless, that is, instructors of the highest caliber can share their knowledge across borders allowing students to attend courses across physical and political 
boundaries. Recognized experts have the opportunity of making information globally available, to anyone interested at minimal costs.

- Accessible, that is, the learning sessions are available $24 \times 7$. Learners are not bound to a specific day/time to physically attend classes. They can also pause learning sessions at their convenience. Particularly, e-Learning can do wonders in case of distance learning curricula.

- Affordable, that is, it allows drastic reduction in the cost of higher education, as the cost of updating the e-notes is negligible as compared to the expenditure on publishing newer updated books. This makes e-Learning a viable option for pharmaceutical institutions and corporate houses both.

However, in the last three decades of executing e-Learning, several probable pitfalls have also been experienced. These are usually as follow:

- Input-intensive, that is, production of high-quality educational material involves spending substantial time (about 50-300 hours per hour of instruction) and effort of the subject experts

- Infrastructure-intensive, that is, it is most effective and cost-effective only when there are adequate number of PC work-stations equipped with high-speed Internet connectivity

- Restricted, that is, queries can be entertained only with regard to the information base available in the package

Apart from academic benefits, e-Learning has been found to be much more productive and economical visà-vis traditional teaching methods in the corporate sector too. Table 3 summarizes the vital pros and cons of each methodology in juxtaposition to each other.

The worldwide e-Learning industry is estimated to be worth over 200 billion USD according to conservative estimates. Also, in the pharma industry of the United States alone, it is estimated that of the $\$ 1$ billion spent annually on sales training/ education, $85 \%$ is allocated for travel and logistics and only $15 \%$ is spent on content. On the other hand, the modern e-Learning methodology offers a much better economical alternative as depicted in Figure 2.

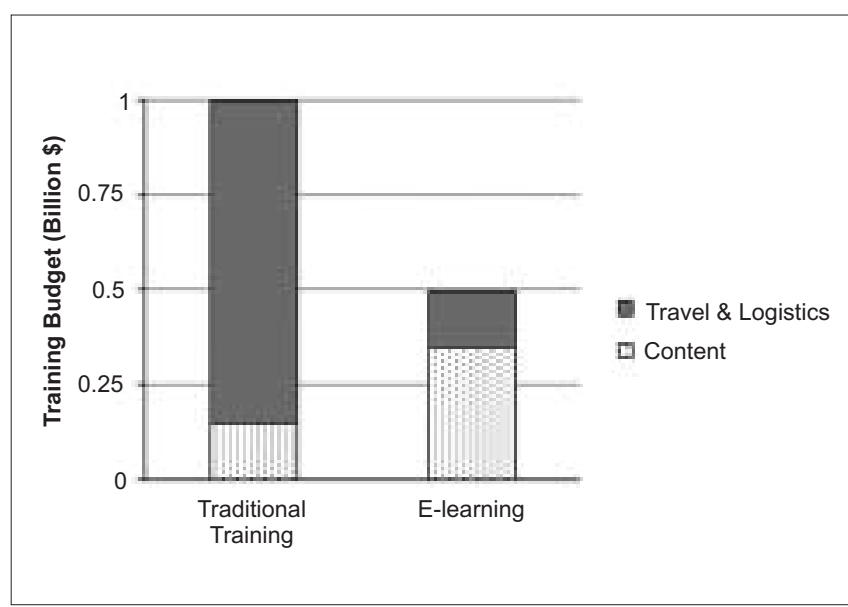

Figure 2: Economics of traditional training and e-Learning in pharma corporate sector

Today, nearly 10 million students participate in on-line learning at institutions of higher education in the United States. Many higher education institutions now offer online classes. On the basis of a poll, the students generally appear to be at least as satisfied with their on-line classes as they are with traditional ones. A study conducted for assessing the efficiency of teaching pain management to pharmacy students established marked superiority of computer-mediated e-Learning vis-à-vis lecture-mediated learning. ${ }^{[1]]}$ Private institutions may become more involved with on-line presentations as the cost of instituting such a system decreases. Properly trained staff must also be hired to work with students on-line. These staff members need to understand the content area, and also be highly trained in the use of the computer and Internet. Online education is rapidly increasing, and online doctoral programs have even developed at leading research universities. ${ }^{[12]}$ Box 3 provides a list of selected e-Learning packages currently available commercially.

Particularly in higher education, there is distinct increasing tendency to create a Virtual Learning Environment, wherein all the aspects of a course are handled through a consistent user interface, standard throughout the institution. A growing number of physical universities, as well as newer online-only colleges, have begun to offer

Table 3: Comparison of learning styles in the corporate sector

\begin{tabular}{ll}
\hline Classroom training & e-Learning \\
\hline More cost-effective for smaller groups & More cost-effective for large, globally dispersed groups \\
Allows for more personalized interaction among participants & $24 \times 7$ access to training, no need to wait for course to be offered \\
"Live" performance of training leaders can be more engaging to some & Provides more "consistent" delivery of course content \\
trainees & \\
Travel opportunity often viewed as a company "perk" & Minimizes time away from work and total time for training \\
Does not require technology upgrades to deliver the lectures & Provide more individualized and self-paced instruction \\
\hline
\end{tabular}




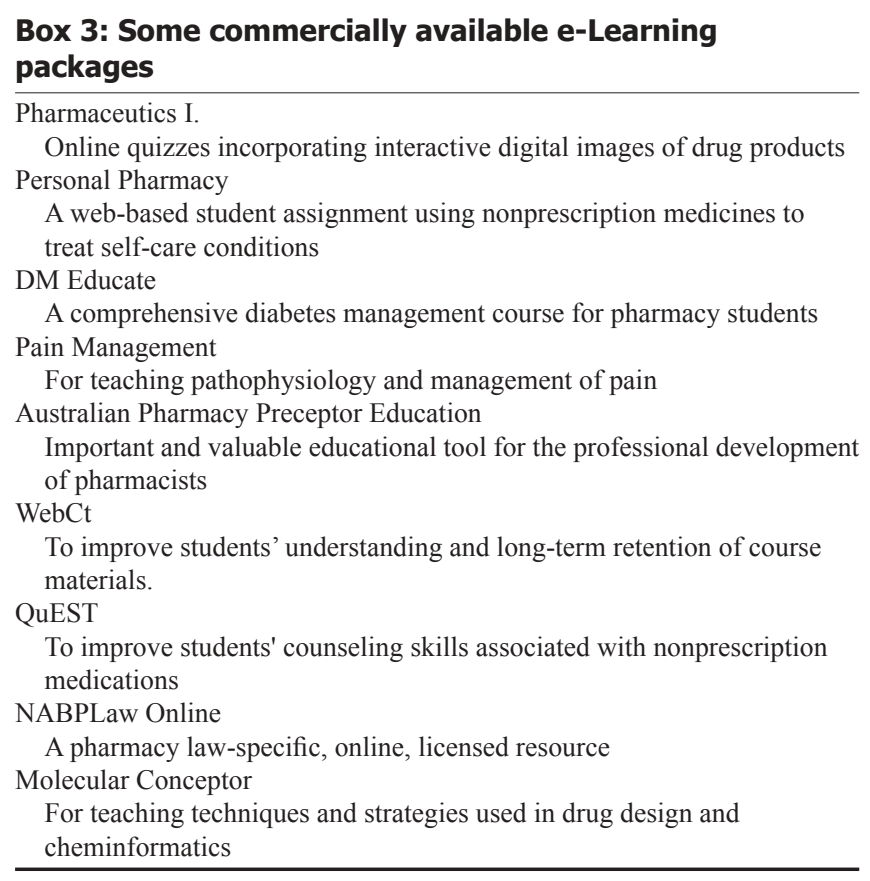

a select set of academic degree and certificate programs via the Internet at a wide range of levels and in a wide range of disciplines. Although some programs require students to attend some campus classes or orientations, yet many are delivered completely online. In addition, several universities offer online student support services, such as online advising and registration, e-counseling, online textbook purchase, student governments and student newspapers too.

\section{PHARMACEUTICAL E-LEARNING: CURRENT INDIAN SCENARIO AND PROSPECTS}

Pharmacy education has been imparted at various universities and institutes in India for more than 60 years. The need to fortify the conventional class room instruction by introducing newer technological techniques such as multimedia has strongly been felt and emphasized at various scaffolds of pharmacy education in India. ${ }^{[13,14]}$ However, the prudent application of computer and web resources is still at primordial state. The level of awareness of students as well as the use of computers in technological streams, other than pharmacy, is nearly comparable to that of the universal standards. By and large, they are far ahead than the pharmacy profession in this respect. With the access to the low-cost microcomputers today, the major reason for the bleak e-Learning milieu in our nation may be the lack of initiative of the educators, coupled with lack of availability of the pertinent software. It is hapless to add that among the several Interactive ComputerAided Teaching (ICAT) software developed by Indian
Society for Technical Education (ISTE), none deals with pharmaceutical profession.

In modern India today, the scientist, students and the traders have ultimately reached to a horizon, where they have to choose practically between "networking" and "not working." Through BSNL and MTNL and private ISPs such as Airtel, Reliance, Sify and Tata, the "Net" is rapidly reaching every home and every business establishment at "high speed." The corporate organizations are establishing "intranet" to implement the access of Internet to their work stations. The computer revolution has triggered our computer industry to produce over 10 million personal computers and scores of indigenously designed supercomputers every year. Despite the recent economic recession, the IT industry has been growing at a phenomenal rate of around 30\%-40\% per annum. Various networks connecting highly powerful computers at the center and certain others at state, district levels, etc. have been established to receive, share or distribute the vital information related on an aspect. The transactions and services at all the major offices, banks, telecommunication centers, trading establishments, travel by air/rail, insurance concerns, etc. have nearly been completely computerized. After initial reluctance and resentment by the traditionalists, the pleasant metamorphosis into this e-cult has directly or indirectly made our life considerably easier, more elegant and efficient. Nevertheless, what is more relevant for us is the likely impact of the e-Learning on Indian pharmacy education.

As an endeavor to introduce this e-cult in pharma education, the need to write computer programs for training pharmacy students and the novice in important professional concepts and rationally include the same in pharmaceutical curricula has been impressed upon at several forums. This is particularly true with aspects requiring graphic manifestation and embodying mathematical complexities such as biopharmaceutics, physical pharmaceutics, physiology and pharmacology, pharmaceutical biotechnology, stability and enzyme kinetics, quality assurance including in-process quality control, TQM, GMP and validation.

University Institute of Pharmaceutical Sciences (UIPS) at Panjab University, Chandigarh, has been a crusader in applications of computer in pharmaceutical sciences in the country, as it is credited with the development of several softwares with direct relevance to pharmaceutical sciences. ${ }^{[15]}$ Many of these have been put into regular use for over a decade not only for data treatment but also in teaching the relevant precepts to the graduate students. 
Despite these humble endeavors, much more is expedient to inculcate e-culture among pharmacy students. Of the limited number of computer packages written in India for educating the pharmaceutical concepts to the undergraduate and graduate students, a lion's share goes to the UIPS, as enlisted in Table 4. Among these software, ZOREL in particular, has been highly sought after in drug industry and academia. ${ }^{[16]}$

These menu-driven and user-friendly softwares provide comprehensive information in an elegant, illustrative and self-operative manner. ${ }^{[17,18]}$ These tend to interact with learner by asking frequent questions and responding to the user-queries through exhibiting facts in textual and/or pictorial form. Optionally, the user can get the text contents of the software printed, partially or completely. The software can be run on any IBM-PC or compatibles and require a minimum of RAM and hard disk space. Educating pharmacy through these programs has been found to be very productive, efficient and exquisite by the students. Nevertheless, there is ardent need to "re-formulate" these products into the "dies" of the more sophisticated modern e-Learning technologies.

At the foyer of 2010, when the world is talking of ITS, networked palm-tops, blue-tooth and advanced computing, a requisite fillip toward e-Learning development and implementation in Indian pharmacy scene needs to be provided. It can be accomplished by a perfect marriage between the modern vision of a pharmaceutical educator and the expertise in IT and/or e-Learning. Teething problems may arise, but by monitoring the student responses, the instructor(s) can quickly decipher the issues that need to be better boldfaced. This can be attained either by comprising additional features in the software packages or supplementing the knowledge propagated through it using the establishmentarian black board approach. Also, the pharmacy teacher himself can develop the e-Learning lessons through the use of any suitable high level languages such as Visual Basic, Visual C, C++ and Java or simpler and effective batch programming and enhancing tools. Authoring language packages requiring little knowledge on computers and capable of setting questions to student replies, handling text and graphics, etc. are also available. Some of the titles are PLATO, CG-TOOLKIT, COURSEWRITER, MICROTEXT, PILOT, LECTUREMAKER, E2TRAIN, COMPOSE, DIRECTOR, TICCIT, AUTHORWARE for IBMcompatibles and HYPERCARD for Macintosh. Some of the indigenously written authoring software tools are also befitting for developing the e-Learning material.

Of late, Government of India has initiated firm steps in this direction. To start with, project SHARDA, a CAL system, has been launched by Municipal Corporation in schools of Delhi. Under the project 487 CAL Centers were established in municipal corporation schools run for urban, poor and slums. And it is estimated that 750,000 children shall be benefited over the period of 5 years of the project, with new and more schools joining the project the number may go further high. And after schools, the concept is percolating to colleges and universities. Indira Gandhi National Open University has started the eGyanKosh program to provide the National Digital Repository to store, index, preserve, distribute and share the digital learning resources developed by the Open and Distance Learning Institutions in the country. The e-Learning portal of Delhi Universities provides education on diverse topics

Table 4: Software on pharmaceutical sciences developed in India

\begin{tabular}{|c|c|c|}
\hline Software & Language & Pharmaceutical Application \\
\hline ZOREL* & FORTRAN & Evaluation of drug release from compressed matrices \\
\hline BIOAWARE* & Batch Enhancer & Bioavailability and bioequivalence concepts \\
\hline CADIS & dBASE & Comprehensive drug information \\
\hline COMPAWARE* & Batch Enhancer & Computer rudiments and their applications in pharmaceutical sciences \\
\hline COPE* & FORTRAN & Pharmacopeial and manufacturer evaluation of solid dosage forms \\
\hline--- & Batch Programming & Pharmaceutical jurisprudence \\
\hline FACTOP* & Batch Enhancer & Optimization of pharmaceutical dosage forms \\
\hline INPRO-SQC* & FORTRAN & In-process statistical quality control \\
\hline MicroM* & FORTRAN & For micromeritic evaluation of particulate pharmaceutical systems \\
\hline NPSTAT* & FORTRAN & Non-parametric statistical evaluation of pharmaceutical data \\
\hline PATCH* & FORTRAN & Evaluation of drug release and permeation kinetics of transdermal systems \\
\hline PROBE* & FORTRAN & Evaluation of protein binding at varied $\mathrm{pH}$, protein conc., temperature \\
\hline PUSHDRUG* & $\mathrm{C}++$ & Community pharmacy shop management \\
\hline QuickTABLET & Q-Basic & Fundamentals of tablet dosage forms \\
\hline STACON* & FORTRAN & Computation of stability constants of drug-metal complexes \\
\hline STAKIN* & FORTRAN & Treatment of data generated during stability studies \\
\hline STOCHA* & FORTRAN & Non-compartmental stochastic pharmacokinetic analysis \\
\hline VesiCAL* & Batch Enhancer & Creating awareness on vesicular drug delivery systems \\
\hline
\end{tabular}

*Developed by the corresponding author and his team 
ranging from botanical identification, basic electronics to physics of semiconductors and remote sensing. And we see no reason as to why it cannot be extended to vital applied areas of pharmaceutical sciences too.

The corporate sector in pharmaceutical sciences can also derive the best prospects with the provisions of such e-Learning tools. Unlike the west, even the large corporates and business houses in India have been slow to adapt to e-Learning. Verily, e-Learning is one of the best ways to train and retrain employees and workforce. Any delay in implementing e-Learning would postpone enormous benefits in terms of the cost-efficacy and efficacy of such tools to improve the ability and performance of their professionals. Although some choose to develop their own training programs, most pharma companies do not have the specialized knowledge and skills required to produce engaging and easy-to-absorb media-rich e-Learning content. Maintaining in-house staff for the purpose is costly as well as extraneous to the pharma business. Thus, it can be more efficient and cost-efficient to outsource the e-instruction projects. Technology-based training can enhance employee performance by delivering job-related content right to their desktops, readily available whenever they need it. That feature is especially appealing to a globally dispersed sales force. Thus, this multimedia-based training is highly flexible and as the course material is self-paced, the employees can use it anytime, anywhere.

Table 5 provides a comprehensive account of favorable aspects and hiccups for the implementation of e-Learning in India.

In developed countries like India, where the e-Learning concept is still new, one crucial element that will make a difference in generating a good response is marketing. This not only holds true for segments such as government and education, but for the corporate sector as well. Regulatory and compliance requirements are frequently changing, and if that was not enough there are also numerous varying regulations across products, services and countries. This can be a difficult situation to fathom, especially for
Indian pharmaceutical companies who must deal with requirements at home as well as in their heavily regulated export markets. Experts are of the opinion view that there needs to be a mindset for the adoption of e-Learning. Every individual must be treated as a potential creator of content. Each one of us must have specialized tools that would help us create well-structured content, allow us to append information, and not make us totally dependent on external sources for content.

A well-designed e-Learning course for corporates provides an opportunity for companies to track results and determine the training materials' overall effectiveness. Built-in practice assessments can provide immediate feedback to each participant, and online graded tests can inform managers about participants' progress before they begin any classroom sessions. Furthermore, e-Learning content is consistent. The presentation of critical material, therefore, remains exactly the same from group to group and from year to year, with modifications only as required. This consistency eliminates glitches in content delivery created by instructor limitations or by varying teaching styles. A well-designed course can also appeal to many learning styles, something that classroom-based training with standard textbook materials fails to address.

The biggest advantage of e-Learning lies in its ability to cover distances. For an organization that is spread across multiple locations, traditional training becomes a constraint. All trainees need to reach a classroom to get trained. Additionally, the trainee's learning pace is not addressed, as all of them are treated as having equal abilities, with little flexibility in terms of timing and completion of the course. Being self-paced, the learner can go through the content repeatedly until he is convinced to have understood. Another advantage is the consistency that e-Learning provides. Verily, e-Learning can indeed be made much more compelling and interesting with the use of multimedia.

Thus, in the current era, Indian pharmacy students should not only be imparted information, information and more information. Instead they need to be basically inspired

Table 5: Scenario of e-Learning technology in India

\begin{tabular}{ll}
\hline Positive side & Negative side \\
\hline Excellent software support & Inept security against plagiarism and piracy \\
Cost-effective hardware infrastructure & Inadequate e-Learning resources and less competent vision of IT specialists \\
English speaking pupils & Bureaucratic red-tapism resulting in delayed justice to litigations \\
High speed Internet connectivity & Lack of proper legislation and timely redressal of complaints \\
High percentage of young population & \\
High computer awareness & \\
Popularity of distance learning & \\
\hline
\end{tabular}


and directed toward access and retrieval from the vast source of information already available on the Net. The chief objective of this "learning super highway" is to teach students that human interaction, interpretation and response are the vehicles with which a netizen can navigate on. Plus, the pupils can be initiated for sharing knowledge through interactions with a galaxy of international scientists and fellow students in varied nooks and corners across the globe. Today, the modern educator has to serve as a manager of the entire information process by sustaining more on the aspects of comprehension and dissemination of information rather than merely on its provision as an outmoded information resource. Powerpoint presentations, literature survey from e-libraries and webinars tend to indulge pupils more firmly into the subject matter. In the post-education real pharmaceutical world too, the pharmacy graduates tackle similar kind of milieu of information enrichment.

Having deliberated upon the promising e-Learning technologies, it is an opportune time when we should categorically resort to the SWOT (strengths, weaknesses, opportunities and threats) analysis in the current scenario and ponder over how these developing technologies can be benefactor to improve the quality of Indian pharmacy education. Table 6 is an endeavor by the authors to have a peep into the same in order to embark upon the strategies to implement e-Learning in a sagacious and pragmatic manner.

\section{Epilogue}

Despite the immense potential, e-Learning in India is still at its infancy. The silver lining in the cloud is that lately it has started gaining prominence at quite a rapid pace. And certainly, the future of e-Learning industry seems to be very bright in India, as the number of Internet users is growing fast. Computer penetration has increased from 2 in 1000 in the year 1999 to 10 in 1000 in the year 2001 and is expected to be more than 100 in 1000 by year 2010. Further, more than half the population of India today is young, that is, aged below 25 years, eager to revolutionize India with its e-resources. In fact, with prices of computers becoming more affordable and Internet speed becoming tolerable, e- Learning can work wonders for the country.

The potential and promises of modern e-culture are high and can yield probably what we aim for. But at the same time, let us make a point here that they cannot be a surrogate to the human character of a teacher. We cannot simply teach only by technology, as there is no machine that can simulate the human mind, the thinking capabilities and capacities of which are limitless, hitherto beyond the scientific reach. The rampant and blind-folded use of the web-based technologies can suppress, rather than stimulate the intuitive and innovative thinking to bring fresh ideas among the learners. Nonetheless, if implemented judiciously and sincerely, e-Learning would

\section{Table 6: e-Learning in Indian Pharmacy Education: Maladies and Remedies}

\begin{tabular}{|c|c|}
\hline \multicolumn{2}{|c|}{ Maladies } \\
\hline$x$ & Reluctance and skepticism for switch-over to newer technologies \\
\hline$x$ & Apprehensions for misuse or abuse of technologies \\
\hline$x$ & Scarcity of technological (e.g., hardware and networking) facilities \\
\hline$x$ & Non-availability of pertinent software to cater pharmacy instruction \\
\hline $\mathbf{x}$ & Lack of awareness among pharmacy educators toward newer technologies \\
\hline$x$ & Inept emphasis of the curricula toward the modern needs and trends \\
\hline$x$ & Want of Institute-Industry interaction for curricular design \\
\hline$x$ & Want of interaction with other technological institutions \\
\hline$x$ & No initiatives for the technological updated institutions and educators \\
\hline $\mathbf{x}$ & Awry governance of pharmacy education by the governing agencies \\
\hline \multicolumn{2}{|c|}{ Remedies } \\
\hline$\checkmark$ & All the pharmacy institutions should be networked. \\
\hline$\checkmark$ & Frequent employment of multimedia aids in teaching pharmacy precepts should be needed to be adopted and encouraged. \\
\hline$\checkmark$ & Teaching should be made globally competitive and accessible by making it interactive rather only information-oriented. \\
\hline$\checkmark$ & For granting monetary aid to apt proposals, AICTE should declare e-Learning technology reinforcement as a thrust area for pharmacy education. \\
\hline$\checkmark$ & Teachers should refurbish their "attitudes" to attain higher "altitudes" in the professional education. \\
\hline$\checkmark$ & $\begin{array}{l}\text { Workshops to provide necessary training to teachers and professionals on newer technologies should be sponsored by governmental agencies and } \\
\text { drug industry. }\end{array}$ \\
\hline$\checkmark$ & Student-interactive and cost-effective educational software should be developed and implemented at appropriate levels in pharmacy education. \\
\hline$\checkmark$ & Frequent projects should be taken up for monitoring the professional needs and suggesting ramifications in the current curricula. \\
\hline$\checkmark$ & $\begin{array}{l}\text { A separate scientific session on "IT in pharmaceutical sciences" should be encompassed in the annual deliberations of Indian Pharmaceutical } \\
\text { Congress. }\end{array}$ \\
\hline$\checkmark$ & $\begin{array}{l}\text { National award(s) should be instituted to motivate the educators and educational institutions contributing significantly toward achieving the } \\
\text { proposed objectives. }\end{array}$ \\
\hline
\end{tabular}


help in reaching out to the pharmaceutical masses in an effective and cost-effective way. History is replete with instances galore where the personal interaction between the learned and the learner had resulted in miraculous effects. The subtle transmission of the qualities of a teacher and motivational forces may bring about remarkable change in the make-up of the taught. Hence, such technologies can fructify only if aptly implemented through the teacher, wherein the latter acts as the master to the former and not otherwise.

\section{ACKNOWLEDGEMENTS}

We gratefully acknowledge the sagacious advice and inputs from Prof. Mandip Sachdeva, FAMU, USA; Prof. Saranjit Singh, NIPER, Mohali, India and Prof. Pardeep Gupta, USP, USA.

\section{REFERENCES}

1. Singh B. Computer-aided education in pharmaceutical sciences. Indian J Pharm Educ. 1997; 31: 93-102.

2. Singh B. C.A.I. in pharmaceutical sciences: Indian scene and prospects. PCCAL-International Bulletin. 1998; 5: 7.

3. Norman G. Effectiveness, efficiency, and e-learning. Adv Health Sci Educ Theory Pract. 2008; 13: 249-51.

4. Singh B, Katare OP. Need of quality education for changing pharma world. Indian J Pharm Educ Res. 2009; 43: 203-18.

5. Singh B, Pathak S, Kumar D, M. Grover. Computer-aided instruction in pharmaceutical education: retrospect and prospects. Proceedings of "EDUCOMP" '96, International Conference on Educational Computing, Chandigarh. March 1996; 329-36.

6. Singh B, Katare OP. Teacher-technology interface: A holistic goal for professional gains. Souvenir of $5^{\text {th }}$ Annual National Convention of
Association of Pharmacy Teachers of India (APTI), Udaipur, India, September 2000; 3-22.

7. Robson J. Web-based learning strategies in combination with published guidelines to change practice of primary care professionals. BrJ Gen Pract. 2009; 59: 104-9.

8. Tse MM, Lo LW. A Web-based e-learning course: integration of pathophysiology into pharmacology. Telemed J E Health. 2008; 14: 919-24.

9. Dantas AM, Kemm RE. A blended approach to active learning in a physiology laboratory-based subject facilitated by an e-learning component. Adv Physiol Educ. 2008; 32: 65-75.

10. Hansen MM. Versatile, immersive, creative and dynamic virtual 3-D healthcare learning environments: A review of the literature. J Med Internet Res. 2008; 10: e26.

11. Jamero DJ, Borghol A, Mihm L. Comparison of computer-mediated learning and lecture-mediated learning for teaching pain management to pharmacy students. Am J Pharm Educ. 2009; 73: 5.

12. Hukkeri VI. Post-GATT pharmaceutical education and research. Global opportunities and challenges. Indian J Pharm Educ Res. 2006; 40: 5-10.

13. Munar MY, Singh H, Belle D, Brackett CC, Earle SB. The use of wireless laptop computers for computer-assisted learning in pharmacokinetics. Am J Pharm Educ. 2006; 70: 4.

14. Persky AM. Multi-faceted approach to improve learning in pharmacokinetics. Am J Pharm Educ. 2008; 72: 36.

15. Singh B, Dutt YC, Singh S, Chopra KS. Computer software with pharmaceutical applications in drug release kinetics, clinical pharmacy and pharmacokinetic analysis. Proceedings of International Symposium on Innovations in Pharm. Sciences and Technology, Ahmedabad. 1990; 18-29.

16. Singh B, Singh S. A comprehensive computer program for study of drug release kinetics from compressed matrices. Indian J Pharm Sci. 1998;60: 358-62.

17. DeLano WL. The case for open-source software in drug discovery. Drug Discov Today. 2005; 10: 213-7.

18. Geldenhuys WJ, Gaasch KE, Watson M, Allen DD, Van der Schyf CJ. Optimizing the use of open-source software applications in drug discovery. Drug Discov Today. 2006; 11: 127-32.

Source of Support: Nil, Conflict of Interest: None declared.

\section{MISSION OF INPHARM}

- To provide an arena to interact and exchange information in order to extend Pharmaceutical knowledge and improve collaboration between different generations of pharmacists nationwide.

- To hear the voice of young pharmacists about present concerns through regular input into pharmacy policy and decision-making.
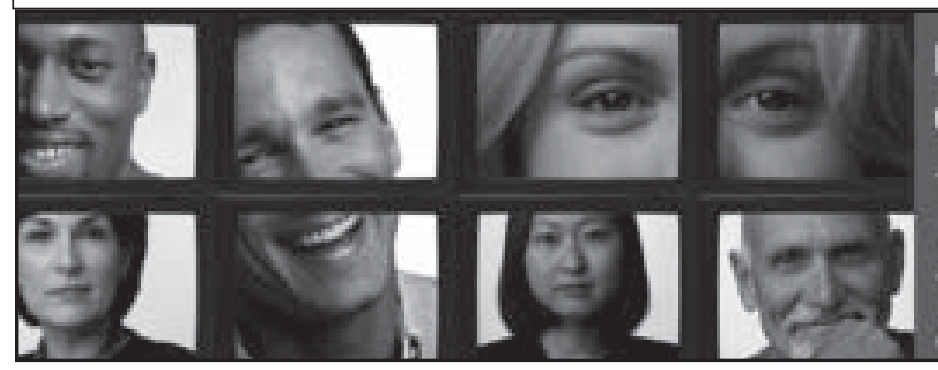

Discover what makes InPharm unique compared to everyone else I!! 